\title{
Melanin as a virulence factor of Paracoccidioides brasiliensis and other dimorphic pathogenic fungi: a minireview
}

\author{
Carlos P. Taborda $\cdot$ Marcelo B. da Silva \\ Joshua D. Nosanchuk · Luiz R. Travassos
}

Received: 27 June 2007/ Accepted: 3 September 2007

(C) Springer Science+Business Media B.V. 2007

\begin{abstract}
Melanin pigments are substances produced by a broad variety of pathogenic microorganisms, including bacteria, fungi, and helminths. Microbes predominantly produce melanin pigment via tyrosinases, laccases, catecholases, and the polyketide synthase pathway. In fungi, melanin is deposited in the cell wall and cytoplasm, and melanin particles ("ghosts") can be isolated from these fungi that have the same size and shape of the original cells. Melanin has been reported in several human pathogenic dimorphic fungi including Paracoccidioides brasiliensis, Sporothrix schenckii, Histoplasma capsulatum, Blastomyces dermatitidis, and Coccidioides posadasii. Melanization appears to contribute to virulence by
\end{abstract}

C. P. Taborda $(\bowtie) \cdot$ M. B. da Silva

Institute of Biomedical Sciences, Department of Microbiology, University of São Paulo, Ave. Prof. Lineu Prestes, 1374, 2 andar, São Paulo, SP 05508-900, Brazil

e-mail: taborda@usp.br

J. D. Nosanchuk

Department of Medicine, Albert Einstein College

of Medicine, The Bronx, NY, USA

J. D. Nosanchuk

Department of Microbiology and Immunology, Albert

Einstein College of Medicine, The Bronx, NY, USA

L. R. Travassos

Department of Microbiology, Immunology and Parasitology, Federal University of São Paulo, São Paulo, SP, Brazil reducing the susceptibility of melanized fungi to host defense mechanisms and antifungal drugs.

Keywords Paracoccidioides brasiliensis . Melanin · Dimorphic fungi - Susceptibility · Pathogenesis

\section{Introduction}

Melanin pigments are multifunctional polymers ubiquitous in nature as they are produced by a remarkable variety of organisms, including bacteria, fungi, plants, and animals. Melanins are negatively charged, hydrophobic, and high molecular-weight compounds, insoluble in aqueous and organic solvents and consequently are difficult to study by conventional biochemical and biophysical techniques. The knowledge about the structure of this pigment is, therefore, limited [1, 2]. They are formed by the oxidative polymerization of phenolic and/or indolic compounds and usually are dark brown or black, although melanin pigments with other colors also exist [1]. A discussion on the contribution of melanin to microbial pathogenesis has attracted considerable interest, with melanin being focused on as a putative virulence factor in fungi.

Although the synthesis of melanin in mammals is typically catalyzed by tyrosinases [3], microbes generally use the polyketide synthase pathway and/ or phenoloxidases (like laccases) [4]. Recognized 
human fungal pathogens that form melanin precursors by the polyketide pathway include Exophiala (Wangiella) dermatitidis, Sporothrix schenckii, Alternaria alternata, Cladosporium carionii, Fonsecaea pedrosoi, Aspergillus niger, A. nidulans, and A. fumigatus [5-9]. The production of DOPA-melanin via phenoloxidases in fungi has also raised scientific interest [10]. The synthesis of melanin in fungi by the DOPA-melanin pathway, also known as eumelanin, requires the presence of exogenous substrate in the form of certain $o$-diphenolic and $p$-diphenolic compounds, such as 3,4 dihydroxyphenylalanine (L-DOPA) [11]. The pathogenic fungi investigated in the production of DOPA-melanins via polyphenoloxidase (a laccase) include many model organisms such as Cryptococcus neoformans [12, 13], Paracoccidioides brasiliensis [14, 15], Histoplasma capsulatum [16], Blastomyces dermatitidis [17], Candida albicans [18], and Coccidioides posadasii [19].

Treatment of melanized cells by enzymatic digestion of the cell wall, proteolysis, chloroform extraction, and boiling in concentrated $\mathrm{HCl}$ results in the recovery of melanin ghosts $[14,20]$. Atomicforce microscopy and scanning electron microscopy images reveal that the surface of melanin ghosts derived from melanized $C$. neoformans cells is composed of discrete granules with roughly uniform dimensions, which corresponds to information known for other melanins [21]. Nuclear magnetic resonance cryoporometry shows that melanin ghosts contain pores with diameters between 1 and $4 \mathrm{~nm}$, in addition to a small number of pores with diameters near $30 \mathrm{~nm}$ [21]. Additionally, elution of graded dextrans has revealed pores in melanized and nonmelanized cells of 4.0 and $10.6 \mathrm{~nm}$, respectively [22].

Some fungi like $C$. neoformans and several molds can produce melanin in the soil, and this characteristic may provide increased resistance to the environmental stressors [23, 24]. Melanized C. neoformans is more resistant to ingestion by environmental amoeboid [25] or nematode [26] species. Melanins also protect fungi from hydrolytic enzymes [27], UV, solar or gamma radiation [28, 29], extreme temperatures [30], and heavy metals and several other toxic compounds [reviewed in 24].

Melanins are immunologically active, however little is known about their relationship with immune systems. Some authors have shown that melanins affect macrophages and reduce proinflammatory cytokines [14, 31, 32]. For example, melanized C. neoformans cells can down-regulate the afferent immune response [33]. Melanization C. neoformans or yeast melanized in vivo elicits inflammatory changes different from nonmelanized or laccasedeficient cells and also interfere with phagocytosis of encapsulated yeast cells [34]. Melanin-binding antibody can also modify infection and melaninbinding antibodies have been isolated from mice with experimental cryptococcosis and humans infected with $F$. pedrosoi $[8,31]$. Melanin-binding antibodies can influence the phagocytosis and intracellular death of diverse fungi [14].

Given the importance of melanin on fungal pathogenesis, it is timely to review recent studies that have expanded our understanding of the impact of melanin production on dimorphic fungi during the infection, the host immune defense, and the resistance to antimicrobial drugs.

\section{Mechanism by which melanin pigments contribute to virulence in human thermally dimorphic fungi}

\section{Paracoccidioides brasiliensis}

Paracoccidioides brasiliensis is the agent of the human systemic disease paracoccidioidomycosis, which affects individuals in endemic areas extending from Argentina to Central America. It is the most prevalent deep mycosis in Latin America and about $80 \%$ of diagnosed patients are from Brazil. Rural workers are the main group at risk for infection, but dwellers of urban centers located on the route of migration movements are also affected. One estimative suggests that ten million people are infected with $P$. brasiliensis and that up to $2 \%$ may develop disease [35-37]. Paracoccidioidomycosis is the 8th most common cause of death due to chronic/recurrent infections and parasitic diseases in Brazil [38]. Infection is thought to occur due to inhalation of conidia that subsequently transform into yeast forms within the lung. Although acquisition of the fungus typically results in asymptomatic infection, infection can progress to acute, subacute, and chronic clinical forms of disease [39]. The virulence of the fungi is directly related to the host immune cellular 
resistance. However, there are differences in virulence between fungal isolates based on a number of attributes, such as melanin, which appear to contribute to pathogenicity.

The ability of $P$. brasiliensis to make melanin pigments was first described by Gómez et al. [15] (Fig. 1). The authors recovered pigmented particles after chemical and enzymatic treatment of conidia and yeasts grown in vitro (on water agar for conidia and in the presence of L-DOPA with yeasts). They also recovered yeast shaped melanin-like particles from infected mouse tissue after chemical and enzymatic treatment. Particles collected from cells in vitro and in vivo were reactive with antibody to melanin. A laccase-like activity was detected in protein extracts of $P$. brasiliensis that was implicated in the enzymatic synthesis of melanin in yeast cells. Additionally, in vitro conidial melanization is quite significant since conidia become pigmented when suspended in pure water indicating a capacity to synthesize melanin-like pigment in the absence of L-DOPA, which would require the fungus to either synthesize its own phenolic precursors for use via laccase or to utilize a different mechanism, such as the polyketide synthesis pathway, to produce melanin [15].

Relatively, little is known about the localization of melanin in human pathogenic fungi but it has been described in intracellular and/or extracellular (e.g., outside cell membrane) spaces. Some fungal melanin is found as part of the cell wall, often recognizable as a distinct and fairly sharply defined outer layer, and some melanin has been found in association with a fibrillar matrix projecting outward from the cell wall of many fungi. For instance, $H$. capsulatum yeast cells produce melanin in their cell wall and also have granules of melanin extending from their outer cell wall [16]. Similarly, pigmented granules have been identified on the surface of $S$. schenckii yeast [5]. In contrast, in $C$. neoformans, exogenous L-DOPA is used for the synthesis of a melanin layer next to the cell membrane and internal region of the cell wall [40]. In contrast, C. albicans produces small spheres of melanin and presumably secretes them as components of biofilm [18]. For P. brasiliensis, scanning electron microscopy reveals that melanized and nonmelanized yeast cells have a smooth surface with no major difference between them, but analysis by transmission electron micrographs shows electrondense granules distributed throughout the cytoplasm and on the cell surface [14].

The ability of melanin to protect microbes from host defense is relevant to antimicrobial therapy because the clinical efficacies of some antimicrobial drugs are complemented by host immune defense mechanisms (reviewed by [24]). Table 1 summarizes the principal differences observed between melanized and nonmelanized yeast cells against host immune defenses and susceptibility to antifungal compounds. Melanized $P$. brasiliensis yeast cells increase resistance to phagocytosis [14]. Since melanins are charged polymers [41] their presence in the cell wall can alter the fungal cell surface charge as shown to occur with melanization in C. neoformans [42],
Fig. 1 Light microscopy of $P$. brasiliensis yeast cells grown in liquid medium without (A) and with (B) L-DOPA. Original magnification $100 \times$

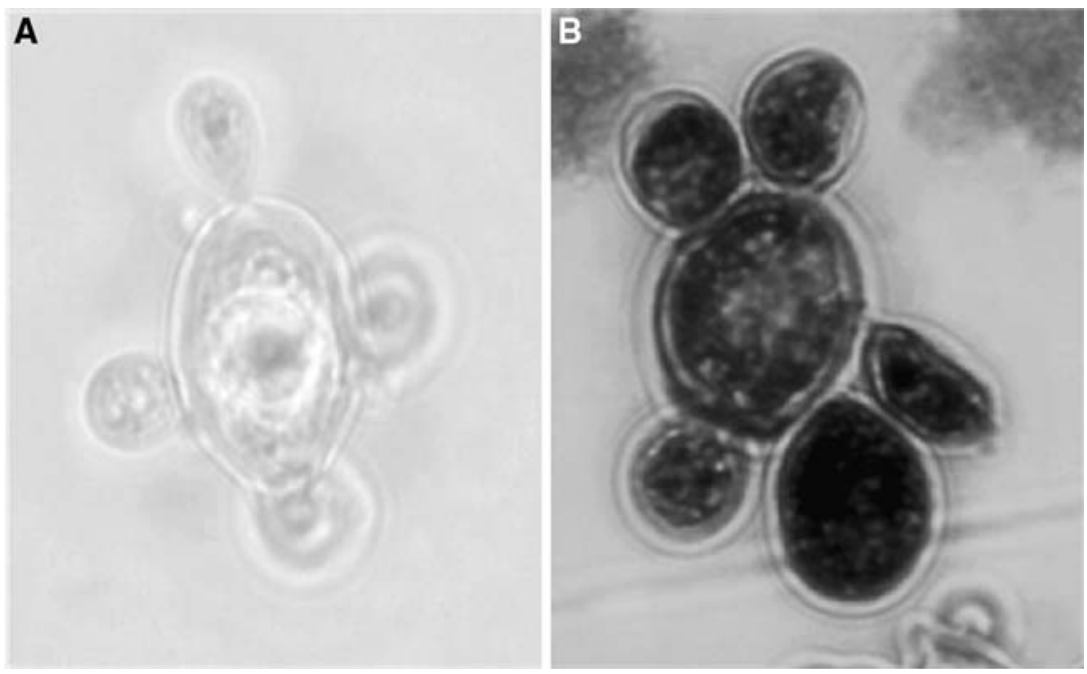


which may contribute to inhibition of phagocytosis. Additionally, melanin can stimulate humoral immune responses. Mice immunized with melanin ghosts from $C$. neoformans produce specific antibodies against melanin [31, 43]. Interestingly although polyclonal antibodies against $P$. brasiliensis melanin can increase phagocytosis of melanized yeast cells by macrophages-like cell lines J774.16 and MH-S (peritoneal and alveolar macrophages, respectively) in vitro [44], polyclonal antibodies against $P$. brasiliensis non-melanin, cell wall antigens do not enhance the uptake of melanized yeast cells [14]. This indicates that melanin interferes with the binding of diverse antibodies resulting in a general reduction in the internalization of melanized cells [14].

In addition to reducing ingestion, melanization protects $P$. brasiliensis against killing by macrophages [14]. Similarly, melanin production in C. neoformans [45], F. pedrosoi [46], S. schenckii [5] and Exophiala spp. [47] enhances resistance to killing by phagocytic cells. The resistance of melanized yeast cells of $P$. brasiliensis to internalization by macrophages in vitro and their increased intracellular survival if ingested can explain the higher fungal burden in the lung of Balb/c mice infected intratracheally with melanized cells, when compared with nonmelanized $P$. brasiliensis [44].

The mechanism of increased survival of pigmented $P$. brasiliensis yeast cells is in part due to the fact that melanization protects $P$. brasiliensis against injury mediated by nitrogen- or oxygen-derived free radicals [44] and also enhances resistance to $\mathrm{H}_{2} \mathrm{O}_{2}$ and hypochlorite as has similarly been shown in C. neoformans, Aspergillus spp., and S. schenckii (Reviewed in $[24,28]$ ). Melanins are highly effective scavengers of free radicals [48] and have electron transfer properties [49]. Electron transfer from free radical species generated in solution to $C$. neoformans melanin has been demonstrated by electron spin resonance spectroscopy [45] and similar spectra have also been generated with melanins from H. capsulatum, S. schenckii, P. brasiliensis, and Pneumocystis spp. (Reviewed in [24, 28]).

Melanin is an antifungal resistance factor, given its ability to reduce the susceptibilities of melanized cells to antifungal drugs [50]. Notably, there is no evidence for the involvement of melanin in drug efflux pumps or in alterations in the synthesis of ergosterol or glucans in the fungal cell wall or cell membrane structures (reviewed in [24]). Melanization of $P$. brasiliensis yeast cells does not affect the cytotoxicity of amphotericin B, ketoconazole, fluconazole, itraconazole, sulfamethoxazole as measured by standard CLSI broth macrodilution procedures for assessing the susceptibility of yeast cells to antifungal drugs [14]. Similar results have previously been observed with melanized and nonmelanized C. neoformans and H. capsulatum [51]. However, an increased resistance of $P$. brasiliensis melanized cells to antifungal drugs mainly amphotericin $\mathrm{B}$, and less pronounced with ketoconazole, fluconazole, itraconazole, and sulfamethoxazole, has been shown using a time-kill assay [14]. The killing assay has also shown that melanized $C$. neoformans and $H$. capsulatum are less susceptibility to amphotericin B and caspofungin, but melanization does not affect cell resistance when fluconazole or itraconazole is used [51].

Laccase is an important virulence factor in many pathogenic fungi. Two different methods have been used to demonstrate that $P$. brasiliensis produces a laccase-like enzyme $[14,15]$. In spite of considerable efforts by several investigators, many aspects of the nature of laccase remain unclear. In $C$. neoformans, the ability of laccase to produce melanin pigments and prevention of iron-dependent Fenton reaction products results in enhanced dissemination of yeast forms to the brain, thus strongly correlating the enzyme with virulence [52, 53]. In C. neoformans, laccase appears to localize predominantly to the outer region of the cell wall where it can interact more directly with extracellullar substances and host immune products without the need for ancillary membrane or cytosolic transporters [54]. For example, oxidation of catecholamines on the outermost region of the cell wall lessens the exposure to oxidized dopamine products, which are cytotoxic in other systems [55]. Besides the oxidative effects on catecholamine, recombinant cryptococcal laccase exhibits iron oxidation activity converting $\mathrm{Fe}^{2+}$ to $\mathrm{Fe}^{3+}$. Iron oxidase activity of laccase may protect $C$. neoformans from alveolar macrophages by oxidation of phagosomal iron to $\mathrm{Fe}^{3+}$ with a resulting decrease in hydroxyl radical formation [56]. In addition, laccase activity has been found to be a marker of stress, as the induction of laccase correlated with substrate starvation and presence of potentially toxic metals [57]. It is currently not known whether the $P$. brasiliensis laccase contributes to 
Table 1 Melanin as virulence factor of P. brasiliensis-general effects and virulence

\begin{tabular}{|c|c|c|c|}
\hline \multirow[t]{2}{*}{ Characteristics } & \multicolumn{2}{|l|}{ P. brasiliensis } & \multirow[t]{2}{*}{ Reference } \\
\hline & Melanized & Nonmelanized & \\
\hline \multicolumn{4}{|l|}{ Morphology } \\
\hline Hyphae & Absent & o & {$[14,15]$} \\
\hline Conidia & Present & o & \\
\hline yeast & Present & o & \\
\hline \multicolumn{4}{|l|}{ Phagocytosis $^{\mathrm{b}}$} \\
\hline Alveolar MØ & $3.9 \pm 0.5$ & $5.8 \pm 0.8$ & [14] \\
\hline Peritoneal M $\varnothing$ & $4.1 \pm 0.4$ & $12.3 \pm 0.5$ & \\
\hline \multicolumn{4}{|l|}{ Adherence } \\
\hline Alveolar MØ & $11.2 \pm 1$ & $8.1 \pm 0.8$ & {$[14]$} \\
\hline Peritoneal M $\varnothing$ & $3.2 \pm 0.9$ & $0.7 \pm 0.2$ & \\
\hline $\mathrm{MIC}^{\mathrm{d}}$ & No difference & No difference & {$[14]$} \\
\hline Killing assay ${ }^{\mathrm{e}}$ & Less susceptible & Susceptible & [14] \\
\hline \multicolumn{4}{|l|}{ Antifungal activity of $M \emptyset^{\mathrm{f}}$} \\
\hline Cfu after $6 \mathrm{~h}$ & $4,583 \pm 117$ & $8,000 \pm 408$ & {$[14]$} \\
\hline Cfu after $12 \mathrm{~h}$ & $3,666 \pm 169$ & $4,166 \pm 236$ & \\
\hline In vivo-cfu g/tissue ${ }^{\mathrm{g}}$ & $30,000 \pm 400$ & $19,000 \pm 800$ & [44] \\
\hline In vitro resistance to oxidants ${ }^{\mathrm{h}}$ & Less susceptible & Susceptible & [44] \\
\hline
\end{tabular}

${ }^{a}$ Detection of presence or absence of melanin in vitro or in vivo

b Phagocytosis of melanized or nonmelanized yeast cells after $24 \mathrm{~h}$ of exposition to mice macrophage-like MH-S (alveolar) and macrophage-like J774.16 (peritoneal)

${ }^{\mathrm{c}}$ Laterally adherent noninternalized yeast cells after $24 \mathrm{~h}$ of exposition to mice macrophage-like MH-S (alveolar) and macrophagelike J774.16 (peritoneal)

d Minimal inhibitory concentration of melanized and nonmelanized yeast cells to amphotericin b, ketoconazole, fluconazole, itraconazole, and sulfamethoxazole

e Antifungal killing assay of melanized and nonmelanized yeast cells to amphotericin b, ketoconazole, fluconazole, itraconazole, and sulfamethoxazole

${ }^{\mathrm{f}}$ Antifungal activity of macrophages after 6 and $24 \mathrm{~h}$ of incubation on melanized and nonmelanized yeast cells with J774.16 previously treated with IFN- $\gamma$

g Cfu from lungs of Balb/c mice intratracheally infected with $3 \times 10^{5}$ yeast cells of melanized and nonmelanized $P$. brasiliensis after 30 days of infection

${ }^{\mathrm{h}}$ In vitro exposition of melanized and nonmelanized yeast cells to chemically generated NO, oxygen-derivated oxidants, chloridefree sodium hypochlorite, and hydrogen peroxide

virulence by mechanisms other than the production of melanin.

\section{Other fungal species}

\section{Sporothrix schenckii}

Sporothrix schenckii is a thermally dimorphic fungus frequently associated with plants and soil and it is the causative agent of sporotrichosis, an important cutaneous and subcutaneous human and animal pathogen $[58,59]$. The mycelial phase predominates in the environment whereas yeast-like forms develop in infected human and animal tissues [60]. Most cases of sporotrichosis are localized to the skin and subcutaneous tissues, although dissemination to osteoarticular structures and viscera may occur in both healthy and immunosuppressed individuals, particularly individuals with AIDS [61]. 
Existing data suggests that the conidia of S. schenckii produce melanin compounds via a 1,8-dihydroxynaphthalene pentaketide pathway [5]. On the selective medium Mycosel, S. schenckii produces visibly pigmented conidia, which are not observed when brain heart infusion and minimal broth are used; hyphae are generally not melanized [62]. However, by using techniques for production of melanin ghosts, melanin-like particles can be recovered from cells grown on Mycosel and minimal broth [63]. Monoclonal antibodies against melanin of S. schenckii have been generated and used to detect melanin or melanin-like compounds in conidia in vitro, and in yeast cells in vitro and in vivo [62].

Melanized S. schenckii yeast is less susceptible to killing by chemically generated oxygen- and nitrogen-derived radicals and UV light than melanindeficient cells [5]. S. schenckii melanin also interferes with yeast cell phagocytosis and diminishes the respiratory burst mediated by human monocytes and murine macrophages [5]. Melanized conidia are more resistant to phagocytosis and killing than nonmelanized conidia and melanin has been associated with scavenging oxygen and nitrogen species [5].

\section{Histoplasma capsulatum}

Histoplasma capsulatum is a thermally dimorphic fungus that occurs most commonly in North and Central America, but the microorganism exists in many diverse areas around the world. Individuals at greatest risk for histoplasmosis are those who have occupational or recreational activities that disrupt the soil, or those who are in contact with accumulated dirt and guano in old buildings, bridges or caves where bats have roosted [reviewed in 63]. Every year, hundreds of thousands of individuals in the US and Central America are infected with $H$. capsulatum. The vast majority of infected persons are either asymptomatic or have a very mild disease that is never recognized as histoplasmosis [reviewed in 63]. Histoplasmosis may, however, progress to life-threatening systemic disease particularly in immuno-compromised individuals $[64,65]$.

H. capsulatum conidia, but not hyphae, produce melanin in minimal medium without the addition of phenolic substrate [16]. Yeast cells also produce melanin, but only when cultivated with phenolic compounds such as L-DOPA or (-)-epinephrine [16]. Scanning electron microscopy demonstrates that melanized conidia and yeast cells grown with L-DOPA formed tufts on the cell surface whereas cells grown in the absence of L-DOPA are smooth [16]. Transmission electron microscopy of melanized yeast cells demonstrated that the cell wall is coated with electron-dense granules [16]. Furthermore, the presence of laccase-like activity has been observed in cytoplasmatic extracts of $H$. capsulatum incubated with L-DOPA [16].

Melanization of $H$. capsulatum has been confirmed by the binding of melanin-specific antibodies to yeast cell walls in infected tissue and the recovery of melanin-like yeast-shaped particles from infected lungs subjected to treatment with acid, denaturing agents and enzymes [16]. Although the CLSI minimal inhibitory concentration (MIC) test with amphotericin B and caspofungin fail to detect differences between melanized and nonmelanized cells, time-kill assays show that melanized cells are significantly less susceptible to amphotericin B and caspofungin [51]. In contrast, no differences were found using fluconazole or itraconazole. The phenomenon of resistance to amphotericin B and caspofungin could be explained by the binding of the drugs to melanin which mitigates their antifungal actions [51].

\section{Blastomyces dermatitidis}

Blastomyces dermatitidis is a thermally dimorphic fungus endemic to the central USA that affects humans and animals. The fungus occurs in the environment as mycelia and forms yeast cells after infecting host tissue. Individuals exposed to the fungus may have an asymptomatic infection or can develop fatal pneumonia even in immunocompetent individuals [66]. In individuals with impaired immunity, the fungus behaves as an opportunistic pathogen after latent infection and can cause widely dissemination disease [67].

A melanin-like pigment from $B$. dermatitidis occurs in conidia, but not hyphae, is produced by mycelium grown on defined chemical medium or brain heart infusion, whereas yeast cells only become pigmented when grown in media supplemented with L-DOPA [17]. Melanin-binding monoclonal antibody 
avidly labels particles isolated from $B$. dermatitidis conidia and yeast by serial treatment with enzymes and hot acid [17]. Additionally, tissue sections of lung from a dog with blastomycosis also reacted with the antibody, indicating that this fungus melanizes in vivo [17]. Consistent with previously described studies, there are no differences in the MIC of melanized and nonmelanized yeast cells for amphotericin $\mathrm{B}$, itraconazole and voriconazole, but time-kill assays demonstrate that melanized yeast cells are significantly less susceptible to amphotericin B [17].

\section{Coccidioides posadasii}

Coccidioides posadasii is a thermally dimorphic endemic fungus in USA, Mexico, Central, and South America [68]. It grows as mycelia in desert and semiarid soils and disturbances in the soil facilitate the dispersal of arthroconidia, which are the infectious propagules. Once inhaled, the arthroconidia convert into the parasitic spherule/endospore phase in tissue [69]. Individuals exposed to this fungus may be asymptomatic, but half of immunologically competent individuals develop an atypical pneumonia characterized by cough, fever, and pleuritic pain often accompanied by rashes, sore throat, headache, arthralgia, myalgia or anorexia [69].

C. posadasii produces melanin. Utilizing the techniques described for other melanized pathogenic fungi, it was observed that the saprobic phase of $C$. posadasii produces melanized arthroconidia but not hyphae [19]. Melanin particles from arthroconidia and intact heat-killed arthroconidia were recognized by melanin-binding monoclonal antibody, indicating the presence of melanin or melanin-like deposits in the residual cell wall material [19]. The parasitic phase was also analyzed. Melanin particles, similar to intact spherule propagules, were obtained after subjecting infected tissues to denaturing enzymes and hot $\mathrm{HCl}$. Additionally, lung tissue immunofluorescence revealed that only endospores within the spherules in the tissue sections reacted with melanin-binding monoclonal antibody with the cell wall of spherules being poorly labeled [19]. Also, intact spherules grown in vitro were not labeled, however spherules grown in vitro devoid of the lipid-rich, membranous spherule outer wall were readily labeled by melanin-binding antibody [19]. Hence, the lipid-rich component of $C$. posadasii effectively blocked reactivity of the melanin-binding antibody, which may affect the pigment's engagement with host effector cells.

\section{Conclusions}

Production of melanin is widespread among microorganisms. In dimorphic fungi like $P$. brasiliensis, S. schenckii, H. capsulatum, B. dermatitidis, and $C$. posadasii, melanin production may promote fungal survival in different environments, augment their resistance to immune effector responses in the infected host, and reduce their susceptibility to antifungal drugs.

Dimorphic fungi appear to produce DHN-melanin in conidia/arthroconidia in nature primarily via a polyketide synthetase pathway. Interestingly, there is an absence of this pigment in hyphae. Melanin production and its effects on the parasitism by yeast cells or spherules/endospores require specific substrates as shown in vitro by addition of L-DOPA or other suitable phenolic compounds in a process mediated by laccase-like enzymes. Melanin and laccase affect the virulence capacity of pathogenic microorganisms. Melanins are a challenge to the defense mechanisms of the hosts, but they are also targets for alternative antimicrobial strategies as exemplified by the fact that passive administration of monoclonal antibodies against $C$. neoformans melanin can prolong the survival of and reduce the fungal burden in C. neoformans-infected mice [43]. A similar result was observed by administration of glyphosate to mice infected with $C$. neoformans resulting in delayed melanization of yeast cells in vivo and prolonged mouse survival [70].

Acknowledgment This work was supported by Fundação de Amparo a Pesquisa do Estado de São Paulo (Fapesp) grant 05/ 02776-0. CPT and LRT are research fellows of the CNPq.

\section{References}

1. Piattelli M, Fattorusso E, Nicolaus RA, Magno S. The structure of melanins and melanogenesis. V Ustilago melanin Tetrahedron 1965;21:3229-36.

2. Hamilton AJ, Gomez BL. Melanins in fungal pathogens. J Med Microbiol 2002;51:189-91. 
3. Sanchez-Ferrer A, Rodrigues-Lopez JN, Garcia-Canova F, Garcia-Carmona F. Tyrosinase: a comprehensive review of its mechanism. Biochem Biophys Acta 1995;1247:1-11.

4. Wheelr MH, Bell AA. Melanins and their importance in pathogenic fungi. Curr Top Med Mycol 1988;2:338-87.

5. Romero-Martinez R, Wheeler M, Guerrero-Plata A, Rico G, Torres-Guerrero H. Biosynthesis and functions of melanin in Sporothrix schenckii. Infect Immun 2000;68: 3696-703.

6. Wheeler MH. Comparisons of fungal melanin biosynthesis in ascomycetous, imperfect and basidiomycetous fungi. Trans Br Mycol Soc 1983;81:29-36.

7. Taylor B, Wheeler MH, Szaniszlo PJ. Evidence for pentaketide melanin biosynthesis in dematiaceous human pathogenic fungi. Mycologia 1987;79:320-2.

8. Alviano CS, Farbiarz SR, De Souza W, Angluster J, Travassos LR. Characterization of Fonsecaea pedrosoi melanin. J Gen Microbiol 1991;137:837-44.

9. Youngchim S, Morris-Jones R, Hay RJ, Hamilton AJ. Production of melanin by Aspergillus fumigatus. J Med Microbiol 2004;53:175-81.

10. Bell AA, Wheeler MH. Biosynthesis and functions of fungal melanins. Annu Rev Phytopathol 1986;24:411-51.

11. Kwon-Chung KJ, Tom WK, Costa JL. Utilization of indole compounds by Cryptococcus neoformans to produce a melanin-like pigment. J Clin Microbiol 1983;18:1419-21.

12. Staib F. Cryptococcus neoformans and Guizotia abyssicnica (syn. G. Oleifera D.C.). Z Hyg 1962;148:466-75.

13. Wang Y, Casadevall A. Melanin, melanin "ghosts", and melanin composition in Cryptococcus neoformans. Infect Immun 1996;64:2420-4.

14. Da Silva MB, Marques AF, Nosanchuk JD, Casadevall A, Travassos LR, Taborda CP. Melanin in the dimorphic fungal pathogen Paracoccidioides brasiliensis: effects on phagocytosis, intracellular resistance and drug susceptibility. Microbes Infect 2006;8:197-205.

15. Gómez BL, Nosanchuk JD, Díez S, YoungchimS, Aisen P, Cano LE, Restrepo A, Casadevall A, Hamilton AJ. Detection of melanin-like particles in the dimorphic fungal pathogen Paracoccidioides brasiliensis in vitro and during infection. Infect Immun 2001;69:5760-7.

16. Nosanchuk JD, Gomez BL, Youngchim S, Diez S, Aisen P, Zancope-Oliveira RM, Restrepo A, Casadevall A, Hamilton AJ. Histoplasma capsulatum synthesizes melanin-Like pigments in vitro and during mammalian infection. Infect Immun 2002;70:5124-31.

17. Nosanchuk JD, van Duin D, Mandal P, Aisen P, Legendre AM, Casadevall A. Blastomyces dermatitidis produces melanin in vitro and during infection. FEMS Microbiol Lett 2004;239(1):187-93.

18. Morris-Jones R, Gomez BL, Diez S, Uran M, Morris-Jones $\mathrm{SD}$, Casadevall A, Nosanchuk JD, Hamilton AJ. Synthesis of melanin pigment by Candida albicans in vitro and during infection. Infect Immun 2005;73(9):6147-50.

19. Nosanchuk JD, Yu JJ, Hung CY, Casadevall A, Cole GT. Coccidioides posadasii produces melanin in vitro and during infection. Fungal Genet Biol 2007;44:517-20.

20. Rosas AL, Nosanchuk JD, FeldmesserM, Cox GM, McDade HC, Casadevall A. Synthesis of polymerized melanin by Cryptococcus neoformans in infected rodents. Infect Immun 2000;68:2845-53.
21. Eisenman HC, Nosanchuk JD, Webber JB, Emerson RJ, Camesano TA, Casadevall A. Microstructure of cell wallassociated melanin in the human pathogenic fungus Cryptococcus neoformans. Biochemistry 2005;44(10): 3683-93.

22. Jacobson ES, Ikeda R. Effect of melanization upon porosity of the cryptococcal cell wall. Med Mycol 2005;43: 327-33.

23. Steenbergen JN, Casadevall A. The origin and maintenance of virulence for the human pathogenic fungus Cryptococcus neoformans. Microbes Infect 2003;5:667-75.

24. Nosanchuk JD, Casadevall A. Impact of melanin on microbial virulence and clinical resistance to antimicrobial compounds. Antimicrob Agents Chemother 2006;50:351928.

25. Steenbergen JN, Shuman HA, Casadevall A. Cryptococcus neoformans interactions with amoebae suggest an explanation for its virulence and intracellular pathogenic strategy in macrophage. Proc Natl Acad Sci USA 2001;98: 15245-50.

26. Mylonakis E, Ausubel FM, Perfect JR, Heitman J, Calderwood SB. Killing of Caenorhabditis elegans by Cryptococcus neoformans as a model of yeast pathogenesis. Proc Natl Acad Sci USA 2002;99:15675-80.

27. Rosas AL, Casadevall A. Melanization decrease the susceptibility of Cryptococcus neoformans to enzymatic degradation. Mycopathologia 2001;151:53-6.

28. Nosanchuk JD, Casadevall A. The contribution of melanin to microbial pathogenesis. Cell Microbiol 2003;5:203-23.

29. Mironenko NV, Alekhina IA, Zhdanova NN, Bulat SA. Intraspecific variation in gamma-radiation resistance and genomic structure in the filamentous fungus Alternaria alternata: a case study of strains inhabiting Chernobyl reactor No. 4. Ecotoxicol Environ Saf 2000;45:177-87.

30. Rosas AL, Casadevall A. Melanization affects susceptibility of Cryptococcus neoformans to heat and cold. FEMS Microbiol Lett 1997; 153:265-72.

31. Nosanchuk JD, Rosas AL, Casadevall A. Antibody response to fungal melanin in mice. J Immunol 1998;160: 6026-31.

32. Mohagheghpour N, Waleh N, Garger SJ, Dousman L, Grill LK, Tuse D. Synthetic melanin suppresses production of proinflammatory cytokines. Cell Immunol 2000;199:2536.

33. Huffnagle GB, Chen GH, Curtis JL, McDonald RA, Strieter RM, Tower GB. Down-regulation of the afferent phase of $\mathrm{T}$ cell-mediated pulmonary inflammation and immunity by a high melanin-producing strain of Cryptococcus neoformans. J Immunol 1995;155:3507-16.

34. Mednick AJ, Nosanchuk JD, Casadevall A. Melanization of Cryptococcus neoformans affects lung inflammatory responses during cryptococcal infection. Infect Immun 2005;73:2012-9.

35. Restrepo A. The ecology of Paracoccidioides brasiliensis: a puzzle still unsolved. Sabouraudia 1985;23(5):323-34 (Review).

36. McEwen JG, Garcia AM, Ortiz BL, Botero S, Restrepo A. In search of the natural habitat of Paracoccidioides brasiliensis. Arch Med Res 1995;26:305-6.

37. Marques-da-Silva SH, Colombo AL, Blotta MH, QueirozTelles F, Balthazar AB, Lopes JD, Camargo ZP. Diagnosis 
paracoccidioidomycosis by detection of antigen and antibody in bronchoalveolar lavage fluids. Clin Vaccine Immunol 2006;13:1363-6.

38. Coutinho ZF, Silva D, Lazera M, Petri V, Oliveira RM, Sabroza PC, Wanke B. Paracoccidioidomycosis mortality in Brazil (1980-1995). Cad Saude Publica 2002;18(5): 1441-54.

39. Franco M, Peracoli MT, Soares A, Montenegro R, Mendes RP, Meira DA. Host-parasite relationship in paracoccidioidomycosis. Curr Top Med Mycol 1993;5:115-149 (Review).

40. Wang Y, Aisen P, Casadevall A. Cryptococcus neoformans melanin and virulence: mechanism of action. Infect Immun 1995;63:3131-6.

41. White LP. Melanin: a naturally occurring cation exchange material. Nature 1958;182:1427-8.

42. Nosanchuk J, Casadevall A. Cellular charge of Cryptococcus neoformans: contributions from the capsular polysaccharide, melanin, and monoclonal antibody binding. Infect Immun 1997;65:1836-41.

43. Rosas AL, Nosanchuk JD, Casadevall A. Passive immunization with melanin-binding monoclonal antibodies prolong survival of mice with lethal Cryptococcus neoformans infection. Infect Immun 2001;69:3410-2.

44. Da Silva MB, Marques AF, Svidzinski A, Nosanchuk, JD, Casadevall A, Travassos LR, Taborda CP. Protective role of Melanin in Paracoccidioides brasiliensis against yeast cells phagocytosis and susceptibility to antimicrobial oxidants (Data not published).

45. Wang Y, Aisen P, Casadevall A. Melanin, melanin "ghosts," and melanin composition in Cryptococcus neoformans. Infect Immun 1996;64(7):2420-4.

46. Cunha MM, Franzen AJ, Alviano DS, Zanardi E, Alviano CS, De Souza W, Rozental S. Inhibition of melanin synthesis pathway by tricyclazole increases susceptibility of Fonsecaea pedrosoi against mouse macrophages. Microsc Res Tech 2005;68(6):377-84.

47. Peltroche-Llacsahuanga H, Schnitzler N, Jentsch S, Platz A, De Hoog S, Schweizer KG, Haase G. Analyses of phagocytosis, evoked oxidative burst, and killing of black yeasts by human neutrophils: a tool for estimating their pathogenicity? Med Mycol 2003;41(1):7-14.

48. Sichel G, Corsaro C, Scalia M, Di Bilio AJ, Bonomo RP. In vitro scavenger activity of some flavonoids and melanins against O2-(.). Free Radic Biol Med 1991;11(1):1-8.

49. Gan EV, Lam KM, Haberman HF, Menon IA. Oxidizing and reducing properties of melanins. $\mathrm{Br} \mathrm{J}$ Dermatol 1977;96(1):25-8.

50. Ikeda R, Sugita T, Jacobson ES, Shinoda T. Effects of melanin upon susceptibility of Cryptococcus neoformans to antifungals. Microbiol Immunol 2003;47:271-7.

51. Van Duin D, Casadevall A, Nosanchuk JD. Melanization of Cryptococcus neoformans and Histoplasma capsulatum reduces their susceptibility to amphotericin B and caspofungin. Antimicrob Agents Chemother 2002;34:3394-400.

52. Rhodes JC, Polacheck I, Kwon-Chung KJ. Phenoloxidase activity and virulence in isogenic strains of Cryptococcus neoformans. Infect Immun 1982;36(3):1175-84.
53. Waterman SR, Hacham M, Panepinto J, Hu G, Shin S, Williamson PR. Cell wall targeting of laccase of Cryptococcus neoformans during infection of mice. Infect Immun 2007;75:714-22.

54. Zhu X, Gibbons J, Garcia-Rivera J, Casadevall A, Williamson PR. Laccase of Cryptococcus neoformans is a cell wall-associated virulence factor. Infect Immun 2001;69(9): 5589-96.

55. Tse DC, McCreery RL, Adams RN. Potential oxidative pathways of brain catecholamines. J Med Chem 1976;19 (1):37-40.

56. Liu L, Tewari RP, Williamson PR. Laccase protects Cryptococcus neoformans from antifungal activity of alveolar macrophages. Infect Immun 1999;67:6034-9.

57. Zhu X, Williamson PR. Role of laccase in the biology and virulence of Cryptococcus neoformans. FEMS Yeast Res 2004;5(1):1-10.

58. Mariat F. Observations sur l'ecologie de Sporothrix schenckii et de Ceraticystis stenoceras en Corse et en Alsace, provinces françaises indemnes de sporothicose. Sabouraudia 1975;13:217-25.

59. Davis BA. Sporotrichosis. Dermatol Clin 1996;14:69-76.

60. Mendonça-Previato L, Gorin PAJ, Travassos LR. Galactose-containing polysaccharides from the human pathogens Sporothrix schenckii and Ceratocystis stenoceras. Infect Immun 1980;29:934-9.

61. Durden FM, Elewski B. Fungal infections in HIV patients. Semin Cutan Med Surg 1997;16:200-12.

62. Morris-Jones R, Youngchim S, Gomez BL, Aisen P, Hay RJ, Nosanchuk JD, Casadevall A, Hamilton AJ. Synthesis of melanin-like pigments by Sporothrix schenckii in vitro and during mammalian infection. Infect Immun 2003;71: 4026-33.

63. Kauffman CA. Histoplasmose: a clinical and laboratory update. Clin Microbiol Rev 2007;20:115-32.

64. Graybill JR. Histoplasmosis and AIDS. J Infect Dis 1988;158:623-6.

65. Wheat J. Histoplasmosis in the acquired immunodeficiency syndrome. Curr Top Med Mycol 1996;7:7-18.

66. Bradsher RW, Chapman SW, Pappas PG. Blastomycosis. Infect Dis Clin North Am 2003;17:21-40, vii.

67. Pappas PG, Threlkeld MG, Bedsole GD, Cleveland KO, Gelfand MS, Dismukes WE. Blastomycosis in immunocompromised patients. Medicine (Baltimore) 1993;72: 311-25.

68. Fisher MC, Koenig GL, White TJ, Taylor JW. Molecular and phenotypic description of Coccidioides posadasii $\mathrm{sp}$ nov., previously recognized as the non-California population of Coccidioides immitis. Mycologia 2002;94:73-84.

69. Cole GT, Xue JM, Okeke CN, Tarcha EJ, Basrur V, Schaller RA, Herr RA, Yu JJ, Hung CY. A vaccine against coccidiodomycosis is justified and attainable. Med Mycol 2004;42:189-216.

70. Nosanchuk JD, Ovalle R, Casadevall A. Glyphosate inhibits melanization of Cryptococcus neoformans and prolongs survival of mice after systemic infection. J Infect Dis 2001;183:1093-9. 